\title{
Development of an Intermediate-Scale Aerobic Bioreactor to Regenerate Nutrients from Inedible Crop Residues
}

Barry W. Finger and Richard F. Strayer

Bionetics Corp.

24th International Conference on Environmental

Systems and 5th European Symposium on Space Environmental Control Systems 
The appearance of the ISSN code at the bottom of this page indicates SAE'sconacht that copies of the peper may be made for personal or intermal uee of epecifie clients. This consent is given on the condition, however, that the copier pay a 55.00 per articte copy tee through the Copyright Clearance Center, Inc. Operations Center, 222 Rosewood Dive, Damers, MA 01923 for copying beyond that permitued by Sections 107 or 108 of the U.S. Copyright Law. This consent does not extend to other kinds of copying such as copying for general distribution, for advertising or promotional purposes, tor creating new collective works, or for resale.

SAE routinely stocks printed papers for a period of three years following date of publication. Direct your orders to SAE Customer Sales and Satisfaction Department.

Quantity reprint rates can be obtained from the Customer Sales and Satisfaction Department.

To request permission to reprint a technical paper or permission to use copyrighted SAE publications in other works, contact the SAE Publications Group.

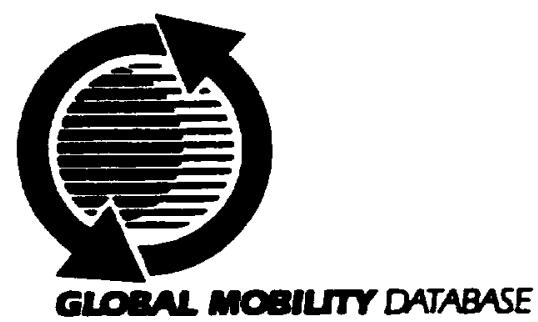

AM SAE papors, standards, and salocted books are abotrected and indoxed in the Global Mobitity Datubese.

No part of this publication may by reproduced in any form, in an electronic retrieval system or otherwise, without the prior written permission of the publisher.

\section{ISSN 0148-7191}

Copyright 1994 Soclety of Automothe Engineers, inc.

Positions and opinions advanced in this paper are those of the author(s) and not necessarity those of SAE. The author is soldhy responsible for the content of the paper. A process is available by which discussions will be primed with the paper if it is published in SAE transactions. For permission to publish this paper in full or in part, contact the SAE Publications Group.

Persons wishing to submit papers to be considered for presentation or publication through SAE should send the manuscript or a 300 word abstract of a proposed manuscript to: Secretary, Engineering Activity Board, SAE. 


\title{
Development of an Intermediate-Scale Aerobic Bioreactor to Regenerate Nutrients from Inedible Crop Residues
}

\author{
Barry W. Finger and Richard F. Strayer \\ Bionetics Corp.
}

\begin{abstract}
Three Intermediate-Scale Aerobic Bioreactors were designed, fabricated, and operated. They utilized mixed microbial communities to bio-degrade plant residues. The continuously stirred tank reactors operated at a working volume of $8 \mathrm{~L}$, and the average oxygen mass transfer coefficient, $k_{L} a$, was $0.01 \mathrm{~s}^{-1}$. Mixing time was $35 \mathrm{~s}$.

An experiment using inedible wheat residues, a replenishment rate of 0.125 day $^{-1}$, and a solids loading rate of $20 \mathrm{gdw}$ day $^{-1}$ yielded a $48 \%$ reduction in biomass. Bioreactor effluent was successfully used to regenerate a wheat hydroponic nutrient solution. Over $80 \%$ of available potassium, calcium, and other minerals were recovered and recycled in the 76-day wheat growth experiment.
\end{abstract}

\section{INTRODUCTION : AEROBIC PROCESSING}

The Controlled Ecological Life Support System (CELSS) Breadboard Project at the Kennedy Space Center has begun the integration of specific Resource Recovery and Biomass Production processes. A primary objective is to regenerate, from inedible crop residues, those inorganic nutrients essential for the continuous production of CELSS candidate crops. The recovered nutrients are incorporated into a hydroponic nutrient solution which is utilized in the Breadboard's Biomass Production Chamber (BPC) to grow higher order food crops such as wheat and soybean. This paper focuses on studies leading to the design, fabrication, and testing of an Intermediate-Scale Aerobic Bioreactor (I-SAB). The bioreactor maintains a mixed microbial community which biodegrades crop residues. Additionally, the microbial mineralization process produces plant nutrients, carbon dioxide for plant photosynthesis, and microbial biomass for secondary food production, e.g. aquaculture.

Mineral recycling research at the KSC breadboard project evolved from research on cellulose conversion of inedible crop residues (11). It was determined that a simple, 2 hour water extraction (ambient temperature) of inedible wheat residue produced a solution that contained significant amounts of many plant nutrients, in addition to water-soluble organic compounds. Subsequent studies demonstrated that "leachate" solution could be used to replenish nutrients in hydroponically grown CELSS crops and that mineral recycling was feasible $(2,3,4)$.

However, it was determined that the soluble organic compounds in the leachate were metabolized by microorganisms resident in the nutrient delivery system. This lead to increased total root respiration (plant plus microbial), the development of microbial biofilms on surfaces of roots and nutrient delivery system components (pipes, trays, tanks, etc.), and increased denitrification potential by the rhizosphere microbial community.

In addition to recycling minerals, the KSC. CELSS Breadboard Project is also assessing the feasibility of secondary production of edible biomass such as fish. To accomplish this goal, it was envisioned that inedible crop residues, including water soluble compounds, would be converted first into microbial biomass that would be suitable for inclusion in a fish diet. Thus, biological processing of the leached particulate residues, containing plant fibrous materials such as cellulose, hemicellulose, and lignin, would probably require that minerals be added to replace those removed during the aqueous extraction.

One solution to these problems is to decompose the soluble organic compounds, converting them to useful microbial biomass, before they are added to the nutrient delivery system. This paper reports on the development of an Intermediate-Scale Aerobic Bioreactor (I-SAB) and the results of studies designed to charecterize and evaluate a combined bioregenerative process. These processes include, mineral extraction/release from inedible biomass, biodegradation of soluble crop residue organics, biodegradation of insoluble crop residue organics with additional release of minerals, and concomitant production of microbial biomass that could be used further (e.g., as a major component of a fish diet). 
Preliminary decomposition studies were carried out, with replication, on a small scale to determine best levels of several key process variables. Experimental conditions were: $50 \mathrm{ml}$ liquid working volume in $250 \mathrm{ml}$ erlenmeyer flasks, $24^{\circ} \mathrm{C}$ incubation temperature, aeration by rotary shaker at 200 RPM, and soybean residue addition of $0.156 \mathrm{gdw}$ day $^{-1}$. Key process variables were daily culture replacement rate $11 / 2$ vs. $1 / 4$ vs. $1 / 8$ ) and soybean residue pretreatment (leached vs. unleached). The key response variable was percent weight loss of added crop residue. After $\mathbf{4 5}$ days, the best decomposition was a $\mathbf{3 8} \%$ weight loss for flasks receiving $1 / 8$ daily culture replacement and unleached soybean residue.

It was observed that the $\mathrm{pH}$ of all treatments increased from 6.5 at day zero to 8.5 at day 45 , so a follow-up study was designed to investigate the effects of $\mathrm{pH}$ control on crop residue decomposition. Replicate flasks were set up as before, but the de-ionized water was replaced with 0.1 molar phosphate buffer at $\mathrm{pH}$ 6.0 vs $\mathrm{pH} 8.0$ in an attempt to control the pH. To determine if a decrease in the daily culture replacement might increase decomposition, 1/16 daily culture replacement was added to the treatments (and the 1/4 treatment was dropped). After 66 days incubation, decomposition in all treatments receiving $\mathrm{pH} 6$ buffer exceeded the corresponding flasks receiving pH 8 buffer. Furthermore, little difference was observed between $1 / 8$ and $1 / 16$ daily culture replacement rates. Of note was that the 0.1 molar buffer concentration only partially controlled $\mathrm{pH}$, as the $\mathrm{pH} 6$ flasks ranged between $\mathrm{pH} 6.8$ and 7.0 and the $\mathrm{pH} 8$ flasks from 8.5 to 8.8 .

Levels of other key bioreactor environmental parameters, i.e., incubation temperature $\left(35^{\circ} \mathrm{C}\right)$, air flow (initially at 0.5 liters air per liter bioreactor liquid), and stirring rate (500 RPM), were selected from fermentation literature (5).

\section{DEVELOPMENT OF AN INTERMEDIATE-SCALE AEROBIC BIOREACTOR (I-SAB)}

Results from the shaker-flask studies indicated that aerobic processing of inedible plant biomass warranted further detailed investigation. However, the addition and harvesting of the solid substrate was found to be labor intensive and operator dependant. It was decided that subsequent studies should be carried out in well instrumented biological reactors. As evident in the shaker-flask studies, the handling and processing of the milled inedible biomass proved to be quite challenging. The prohibitive cost and marginal effectiveness of commercial bioreactors to adequately process the solids laden slurry resulted in a decision to design and construct a bioreactor in-house.

DESIGN OBJRCTIVES - At the start of the project a number of design objectives were established. The list included traditional goals as well as those specific to the processing of CELSS inedible biomass. The following section identifies the primary design objectives established for the development of an Intermediate-Scale Aerobic Bioreactor (I-SAB).

Solids Loading - Many industrial aerobic fermentation processes operate with solids loading as high as $50 \mathrm{~g} \mathrm{~L}^{-1}$, however these high concentrations can only be maintained under special circumstances (6). Chemical anti-foams or mechanical foam breakers are often employed to control the foaming problems associated with these highly aerated systems (7). Additionally, the feed stream for many of these processes is soluble and the mixing problems associated with insoluble substrates is absent. Most waste-water treatment facilities maintain solids loading no higher than $5 \mathrm{~g} \mathrm{~L}^{-1}(6)$. Because of the low loading rate, these systems require minimal or no use of antifoams and do not require high gas sparging rates. This is desirable since it is not likely that chemical antifoams would be available in an operational CELSS and high gas sparging implies a high energy cost. In order to minimize fluid working volume, a high solids loading rate is preferred, however, the use of anti-foams or complex mechanical foam breakers is not. Therefor, the bioreactor was designed to handle a solids loading of $50 \mathrm{~g} \mathrm{~L}^{-1}$ or less, and do so without the aid of chemical anti-foams or a complex mechanical foam breaker.

Working Volume - The bioreactor should be capable of processing working volumes ranging between 6 and $12 \mathrm{~L}$. This allows for a wide range in operational parameters such as the dilution rate (ratio of in-flow rate to working volume) and the overall production rate of the bioreactor. For example, given a typical dilution rate of 10 day $^{-1}$, the flow rate through the reactor would be 0.6 and $1.2 \mathrm{~L} \mathrm{day}^{-1}$ for $\mathrm{a} 6$ and 12 $L$ working volume respectively. It was determined that these flow rates would be high enough to support future plant growth studies (8).

Mixing and Aeration - A primary design objective was that uniform mixing of the solid, liquid, and gas phases be achieved. Effective power input implies good mixing by the impeller and the gas sparger. It is important to ensure that the impeller Reynolds Number is high and therefore in the turbulent range. The oxygen mass transfer coefficient, $k_{L} a$, is intimately tied to the mixing characteristics and must be maintained at a level that is not limiting to the biodegradation process. Typical values of $k_{L}$ a range between $3 E-4$ and $3 E-3 s^{-1}$ for waste water treatment and up to $0.1 \mathrm{~s}^{-1}$ for bacteria and yeast fermentations (6). It has also been shown that the minimum dissolved oxygen concentration, above which $\mathrm{O}_{2}$ is not limiting to microbial growth, ranges between 0.1 and $1.6 \mathrm{mg} \mathrm{L}^{-1}$ (7). Therefor, the aeration and mixing systems should sustain adequate values of $k_{1} a$ and maintain the DO above $1.6 \mathrm{mg} \mathrm{L}^{-1}$.

Feeding and Harvesting - As previously discussed, feeding and harvesting during the shakerflask studies were labor intensive and time consuming. 
Since it was anticipated that I-SAB would be used in long duration studies (up to 6 months), it was important that these processes be improved.

Environmental Monitoring and Control - In addition to meeting aeration requirements, the I-SAB control system was designed to maintain temperature and $\mathrm{pH}$ at predetermined set-points. Since foaming could occur at the flow rate required to maintain proper DO, foam control was provided to prevent particle and liquid entrapment in the exiting gas stream. Controlled parameters such as stirring, feeding, and aeration rates, temperature, and $\mathrm{pH}$ as well as other primary process parameters such as $\mathrm{CO}_{2}$ production and dissolved oxygen were continuously monitored and recorded.

\section{I.SAB DESIGN}

I-SAB was designed as a Continuously Stirred Tank Reactor (CSTR), a well documented design that has been used extensively in both research and industry. The traditional CSTR design includes a cylindrical mixing vessel with either a flat or domed bottom, a shaft mounted mixing impeller, and a gas sparger. CSTRs are adaptable to continuous culture and amenable to scale-up. More detailed analysis of CSTR design and operation can be found in references $(5,6,7,9,10)$. Three I-SAB's were designed and fabricated between September, 1992 and January, 1993. The following section describes the various subsystems of a complete 1-SAB unit.

CONTAINMENT VESSEL - Each I-SAB vessel is $395 \mathrm{~mm}$ in height and $254 \mathrm{~mm}$ in diameter. For working volumes ranging between 6 and $12 \mathrm{~L}$, the height/diameter ratio ranges between 0.5 and 1 . Wetted materials of construction are stainless steel and lexan. For ease of fabrication a flat rather than domed bottom was constructed. Access ports are located at the $6,8,10$, and $12 \mathrm{~L}$ levels of the vessel. Two large rectangular viewing ports allow visual inspection. Figure 1 shows a detailed view of I-SAB.

STIRRER ASSEMBLY - The stirrer assembiy utilizes a sealed magnetic drive system which eliminates rotating seals and their corresponding complexity. A $40 \mathrm{~W}$, variable speed gear motor (Model 104. Talboys) is attached to an outer rotor which is lined with permanent earth magnets. An inner magnetlined rotor is separated from the outer rotor by a stainless steel cap. An O-Ring seated between the cap flange and the lid of the bioreactor creates an impermeable seal. A stainless steel shaft extends through a bearing block and into the vessel. A $51-\mathrm{mm}$ diameter marine impeller is fixed on the end of the shaft and is located $51 \mathrm{~mm}$ above the tank bottom.

Maximum stirrer speed is 750 RPM with a nominal operating speed of 525 RPM. The impeller Reynolds Number $\left(R e_{1}\right)$ is given by:

$$
\operatorname{Re}=\frac{N D^{2}}{v}
$$

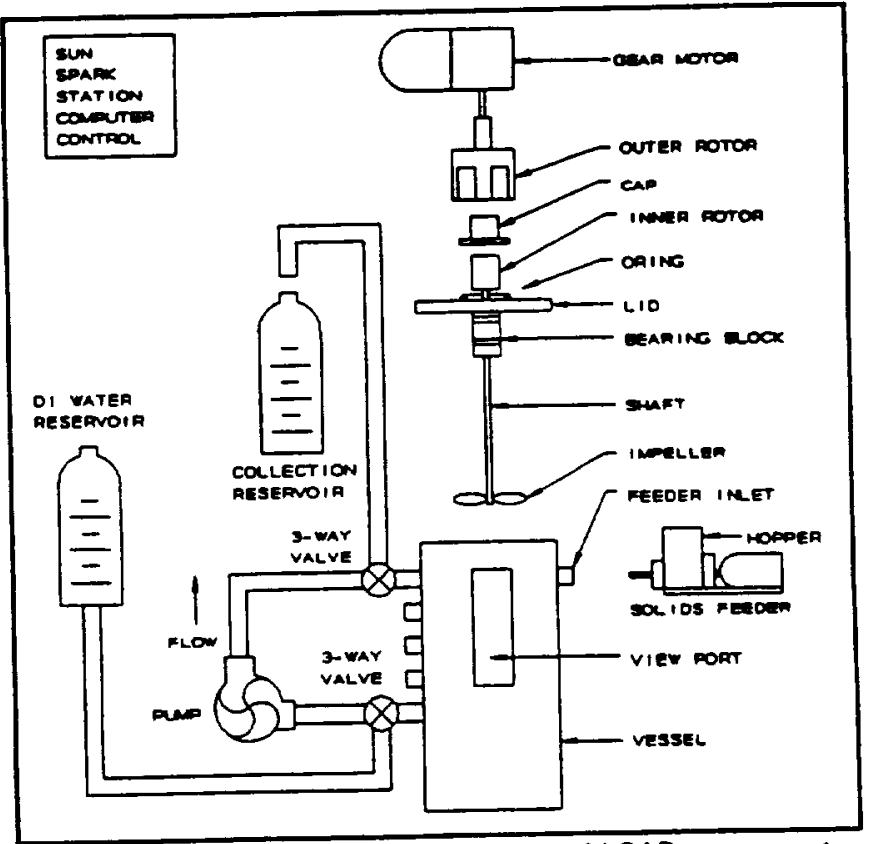

Figure 1. Identification and configuration of I-SAB components.

where: $N$ is the rotational speed

$D$ is the diameter of the impeller

$v$ is the kinematic viscosity of the fluid

Assuming the fluid is water $\left(v=1 E-6 \mathrm{~m}^{2} \mathrm{~s}^{-1}\right)$, $\mathrm{N}=525 \mathrm{RPM}, \mathrm{D}=51 \mathrm{~mm}$, and utilizing equation (1), $R e_{\text {, }}$ for the stirrer assembly is calculated to be 2.3E4. This result confirms that the stirrer will operate in the turbulent region and therefor good mixing can be expected around the impeller.

Another technique used to assess mixing potential is to measure the power input of the stirrer into the system. Power input by an impeller $\left(P_{1}\right)$ is given by (9):

$$
P_{I}=N_{P} \rho N^{3} D^{5}
$$

where: $N_{p}$ is the power number

$\rho$ is the fluid density

$N_{p}$ is a complex function of the geometry of a mixing system. For a baffled tank and marine impeller, Tatterson has estimated $N_{p}$ to be 0.6 (9). For an unbaffled tank with $a R_{1}$ of $2.3 E 4$ and using Tatterson's correlation, $N_{p}$ was found to be 0.2. I-SAB does not utilize traditional baffles, however, the top mounted $\mathrm{pH}$, dissolved oxygen, and temperature probes, and the gas sparger act like baffles and disrupt rotational flow. Therefor, for the purposes of this analysis a value of $N_{p}=0.4$ was chosen. Assuming $\rho=1 \mathrm{~kg} \mathrm{~m}^{-3}, \mathrm{~N}=525$ RPM, $\mathrm{D}=51 \mathrm{~mm}$, and substituting into equation (2), $P_{1}$ is found to be $9.24 E-2 W$. At a nominal working volume of $8 \mathrm{~L}$ the power to volume ratio, $P N$, is $1.16 \mathrm{E}-2 \mathrm{~W} \mathrm{~L}^{-1}$.

AERATION - Facility compressed air was utilized in the I-SAB aeration system. Coalescing air filters (Model DX and BX, Balston) remove $99.99 \%$ of 
0.1 micron or larger particles and droplets. A thermal mass flow controller (Sierra Instruments) maintained the flow rate at a user defined set-point between 0 and $15 \mathrm{~L} \mathrm{~min}^{-1}$. A 76-mm diameter ring sparger, located 25 $\mathrm{mm}$ off the bottom, aerates the bioreactor. Power input by the sparger $\left(P_{3}\right)$ is given by $(9)$ :

$$
P_{s}=Q P g H
$$

where: $Q$ is the flow rate of the gas

$g$ is the local gravitational level

$H$ is the sparging height

The sparging height ( distance between sparger and liquid surface) for a volume of $8 \mathrm{~L}$ is $142 \mathrm{~mm}$. Substituting values of $Q=5 \mathrm{~L} \mathrm{~min}{ }^{-1}, \rho=1 \mathrm{~g} \mathrm{~cm}^{3}, g=$ $9.8 \mathrm{~m} \mathrm{~s}^{-2}$, and $H=142 \mathrm{~mm}$ into equation (3) results in a $P_{s}$ of $0.116 \mathrm{~W}$. For an $8-L$ working volume, $P_{s} N$ is calculated to be 1.45E-2 $\mathrm{W} \mathrm{L}^{-1}$.

SOLIDS FEEDER - Ground inedible biomass 11 $2 \mathrm{~mm}$ particle size) was introduced into the bioreactor by an auger feeder. The biomass was placed in a $\mathbf{4 0 0}$ $\mathrm{cm}^{3}$, stainless steel hopper. Once the lid was in place, the hopper was sealed to ensure that no moisture laden air back-flows into the hopper from the bioreactor, as this would have led to clumping of the biomass and incomplete feeding. A motor driven, auger-type screw located in the bottom of the hopper conveyed solids out of the hopper and into the bioreactor, just above the liquid level. A 1600 RPM bin vibrator (Model SPR20, Vibcol prevented bridging of the solids and assured a uniform flow. The volumetric flow rate for dried wheat inedible biomass could be varied between 10 and $30 \mathrm{~cm}^{3} \mathrm{hr}^{-1}$.

HARVESTER ASSEMBLY -- Harvesting was accomplished by circulating bioreactor contents through an external loop and back into the bioreactor. A centrifugal pump (Model AC-4C-MD, March Manufacturing) moved the slurry through the loop at 5 $L \mathrm{~min}^{-1}$. Two 3-way valves were used to harvest the slurry and add deionized water. As shown in Figure 1. a 3-way valve, located just before the return port, was used to divert a part of the flow to a collection reservoir during harvest. This system assured uniform mixing and provided repeatable representative sample collection. After harvesting was complete, deionized water was added via the second 3-way valve and circulated through the external loop to flush remaining solids into the bioreactor and replenish the liquid volume.

pH AND TEMPERATURE CONTROL - Hydrogen ion concentration was maintained by injecting a $1 \mathrm{~N}$ nitric acid solution into the bioreactor when the $\mathrm{pH}$ rose above a user defined set-point. A combination type pH electrode and transmitter (Model PHE-6510 and PHTX92, Omega Engineering) continuously monitored $\mathrm{pH}$ in the bioreactor. Acid was pumped out of a graduated reservoir by a metering pump (Model 210-5R, March Manufacturing), and through a solenoid valve and added through the bioreactor's lid. A $0.5-\mathrm{mm}$ diameter nozzle located on the acid addition inlet produced a thin, high pressure stream of acid directed at the liquio surface. The jetting action of the stream penetrated the foam layer and improved dispersion of the acid within the bioreactor.

Temperature control was maintained by an external heating jacket. Heated water from a circulating water bath (Model 2095, Forma Scientific) was pumped through copper coils which were soldered to the external wall of the bioreractor. An insulation jacket comprised of $25.4-\mathrm{mm}$ closed-cell foam insulation encased the bioreactor vessel and the heating coils. A thermocouple probe measured temperature inside the bioreactor. Temperature control was effected by regulating the flow of water through the heating coils with a computer controlled solenoid valve.

ENVIRONMENTAL MONITORING AND CONTROL - As previously discussed, pH, temperature and aeration mass flow were monitored and controlled. Additionaliy, a dissolved oxygen probe and transmitter (Model 4, Oxyguard) continuously monitored DO in the bioreactor. Also, bioreactor headspace gas was circulated through a carbon dioxide analyzer (Model LI6251. LI-COR/ to obtain the $\mathrm{CO}_{2}$ concentration of the exiting gas stream.

Hardware for monitoring and control included a SUN Sparc Station and OPTO-22 digital and analog input/output boards. Software developed in-house (UNDACE V1.9), was used for monitoring and control and acted as the primary information interface between the operator and I-SAB. All monitored parameters were permanently recorded at 5 minute intervals on a Hewlett Packard Model 9000 1-50 mainframe computer. For more information on computer monitoring and control refer to reference (11).

\section{RESULTS AND DISCUSSION}

TEST RESULTS - I-SAB testing was conducted during the month of January, 1993. Testing included validation of the various pumps, valves, seals, and stirring motors. The harvest and water addition system and the solids feeder were also tested to ensure proper operation during experimental runs. Mixing time was measured with a working volume of $8 L$ ldeionized water), aeration flow of $5 \mathrm{~L} \mathrm{~min}^{-1}$, and a stirrer speed of 525 RPM. After initially adjusting the $\mathrm{pH}$ to $6.0,3$ $\mathrm{mL}$ of $1 \mathrm{~N} \mathrm{HNO}_{3}$ was added to the bioreactor. The $\mathrm{pH}$ stabilized at 2.4 within $35 \mathrm{~s}$.

The volumetric oxygen mass transfer coefficient $\left(k_{L} a\right)$ was measured using the static gassingout method (12). I-SAB 3 was filled with $8 \mathrm{~L}$ DI water and continuously sparged with nitrogen to remove all dissolved oxygen. It was determined that measurement of $k_{1} a$ in DI water was sufficient since the viscosity and density of the actual slurry were approximately equal to that of water $\left(\rho=1.006 \mathrm{~g} \mathrm{~cm}^{-3}\right.$, $v=10 \mathrm{cp}$. After sparging with $\mathrm{N}_{2}$, stirrer speed and 


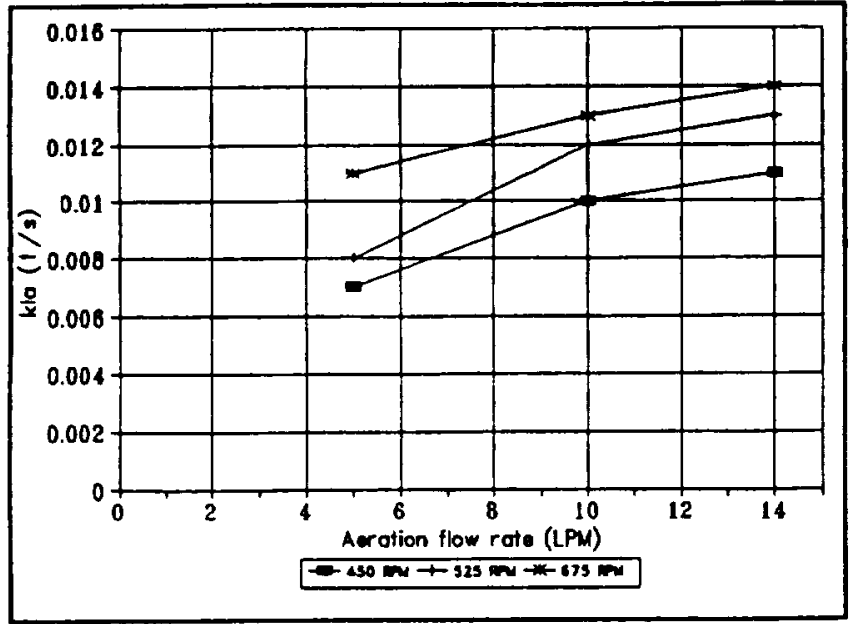

Figure 2. Plot of $k, a$ verses aeration flow rate for three different stirrer speeds.

aeration were started at pre-selected values. Immediately after the start of aeration, the DO concentration was monitored and recorded until a steady-state concentration was achieved. DO-time profiles were recorded for 9 combinations of stirrer speed and aeration. The time course of DO after the start of aeration is given by:

$$
\ln \left(1-\frac{c}{c^{*}}\right)=k_{L^{a}} t
$$

where: $c$ is the instantaneous DO concentration $c^{*}$ is the saturation DO concentration $t$ is time

The slope of the line generated by plotting In (1$c / c^{\circ}$ ) verses $t$, is equal to $k_{L} a$. The results of the 9 runs are shown in Figure 2. Values of $k_{L}$ a ranged between 0.007 and $0.014 \mathrm{~s}^{-1}$. These values fall within the range reported for waste water treatment (6).

Temperature control was found to be quite stable and was routinely maintained at $+1-0.2^{\circ} \mathrm{C}$. Occasionally the water level in the hot water circulating bath dropped below a minimum requirement for continuous circulation. This resulted in transient lower bioreactor temperatures, but was found to have no long-term effects on bioreactor operation.

Generally, $\mathrm{pH}$ control was maintained at $+1-$ $0.1 \mathrm{pH}$ units throughout each operation. However, spurious electrical noise generated by the stirrer motor occasionally corrupted the $\mathrm{pH}$ transmitter signal and impeded control. Replacement of the stirrer motor brushes or stretching of their compression springs alleviated the problem.

EXPERIMENTAL RESULTS - A series of eight short I-SAB runs were used to determine the effects of three key process variables on response variables. Process variables were $1 / 4$ vs. 1/8 culture volume replacement day $^{-1}, 20$ vs $40 \mathrm{gdw}$ wheat residue

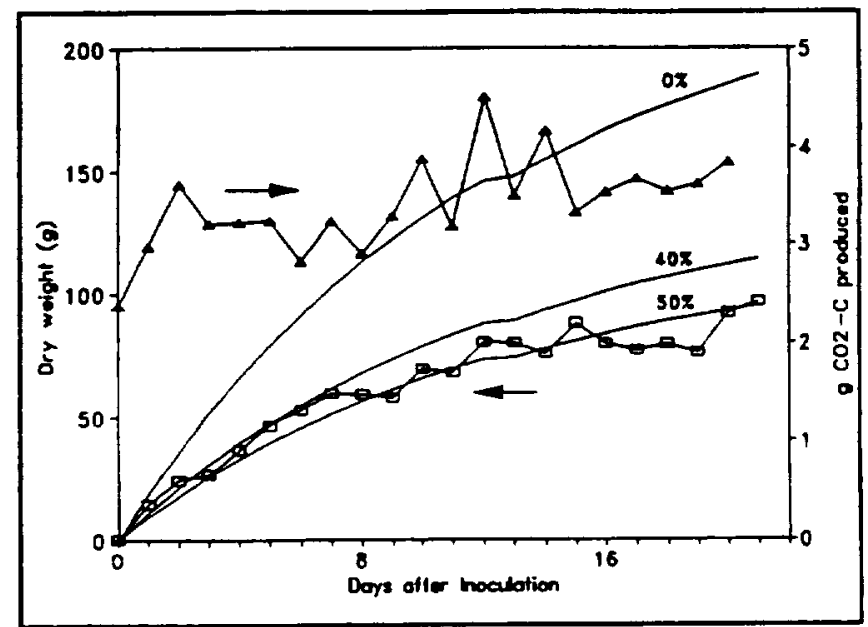

Figure 3. The upper plot shows daily $\mathrm{CO}_{2}$ production, the lower plot shows the time-course of microbial decomposition of crop residues, and the solid curves represent theoretical decomposition of 0,40 , and $50 \%$.

addition day ${ }^{-1}$, and with/without solids recycling (about1/3 of harvested solids were returned to the bioreactor). Response variables were dry weight loss and $\mathrm{CO}_{2}$ production. Run durations were 14 days for $1 / 4$ culture replacement and 21 days for $1 / 8$ culture replacement.

Figure 3 shows the time-course of microbial decomposition of added crop residues during one of the eight bioreactor runs. Three theoretical lines are also plotted. The line labeled $0 \%$ represents dry weight of bioreactor contents if no decomposition occurred, while the lines labeled 40 and $50 \%$ represent dry weights if these amounts of the added biomass were decomposed, or lost. The plot of observed dry weight ranges between these two theoretical lines for most of the 21 day run. At harvest, $48 \%$ of added biomass had been decomposed, presumably to carbon dioxide.

Decomposition has been underestimated by dry weight loss because soluble minerals, released from the crop residue into the liquid, are included. Future studies will compare the weight loss of volatile solids (i.e., ash free dry weight) to correct for this underestimation. The dry weight measurements further underestimate decomposition because they include both undigested crop residues and microbial biomass. Another analytical problem has been finding a method to independantly determine the mass of crop residues and microbial biomass. Research is in progress to solve this problem for such a complex substrate.

The dry weight losses for all eight experimental bioreactor runs are shown in Table I. In general, decomposition of wheat residues was better at the lower daily culture replacement rate tested, $1 / 8$ day $^{-1}$

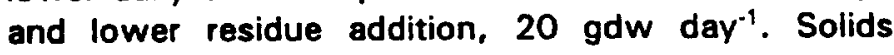
recycling seemed to also provide for greater decomposition, but dry weight losses were not as dramatically different as for the other two process parameters.

A typical plot of daily $\mathrm{CO}_{2}$ production and dissolved oxygen concentration during one of the 


\begin{tabular}{|c|c|c|c|c|}
\hline $\begin{array}{c}\text { Culture } \\
\text { Replacement }\end{array}$ & $\begin{array}{l}\text { gdw added } \\
\text { per day }\end{array}$ & $\begin{array}{c}\text { Solids } \\
\text { Recycled }\end{array}$ & $\begin{array}{l}\text { Weight } \\
\text { Loss (\%) }\end{array}$ & $\begin{array}{l}\text { Carbon to } \\
\mathrm{CO}_{2}-\mathrm{C}(\%)\end{array}$ \\
\hline \multirow[t]{4}{*}{$1 / 8$} & 20 & $\mathbf{N}$ & 44 & 48 \\
\hline & & $Y$ & 50 & 47 \\
\hline & 40 & $\mathbf{N}$ & 40 & 29 \\
\hline & & $\mathrm{Y}$ & 41 & 28 \\
\hline \multirow[t]{4}{*}{$1 / 4$} & 20 & $N$ & 31 & 47 \\
\hline & & $Y$ & 34 & 41 \\
\hline & 40 & $\mathbf{N}$ & 30 & 23 \\
\hline & & $Y$ & 34 & 26 \\
\hline
\end{tabular}

bioreactor runs is shown in Figure 4. When the dried wheat residue was added at about 08:30 there was an immediate stimulation of carbon dioxide production from just over $3 \mathrm{ml} \mathrm{min}-1$ to about $14 \mathrm{ml} \mathrm{min}^{-1}$ with a concomitant decrease in dissolved oxygen from 5.5 to $1.5 \mathrm{mg} \mathrm{L}^{-1}$. The most likely reason for this response was rapid microbial degradation of soluble organic compounds released from the crop residue. With time, both carbon dioxide production and dissolved oxygen returned to more stable levels.

The rapid decrease in dissolved oxygen was undesirable. Under anaerobic or anoxic conditions, microbial production of potential phytotoxic compounds (e.g., low molecular weight organic acids) can occur. Second, anaerobic conditions also favor microbial denitrification, or conversion of inorganic nitrate into nitrogen gas. The problem was solved in subsequent bioreactor runs by adding solids over a two to three hour period instead of all at once. To perform this task, a solids addition hopper with an auger located in the bottom was designed, fabricated, and installed on the outside of the bioreactor, so solids entered about $150 \mathrm{~mm}$ above the liquid level.

The daily carbon dioxide data, as shown in Figure 4, was used to caiculate the sum of $\mathrm{CO}_{2}$ produced each day. These summations for one of the runs are plotted in Figure 3, along with the corresponding dry weights taken at the same time. For this run, daily $\mathrm{CO}_{2}$ production was stable from the start, with a slight increase from 2.9 at the beginning to $3.8 \mathrm{~g} \mathrm{CO}_{2}-\mathrm{C}$ per day at harvest. $\mathrm{CO}_{2}$ production during the first seven days was higher than anticipated and does not correspond to the slower build up of dry weight losses. The soluble organic compounds that are "leached" from the crop residues are more easily and rapidly degraded than the cellulose and hemicellulose structural polysaccharides that account for ca. $50 \%$ of $B P C$ wheat crop residues (1). The high $\mathrm{CO}_{2}$ production rates early in each run probably reflect the rapid growth and degradation of soluble organic compounds,

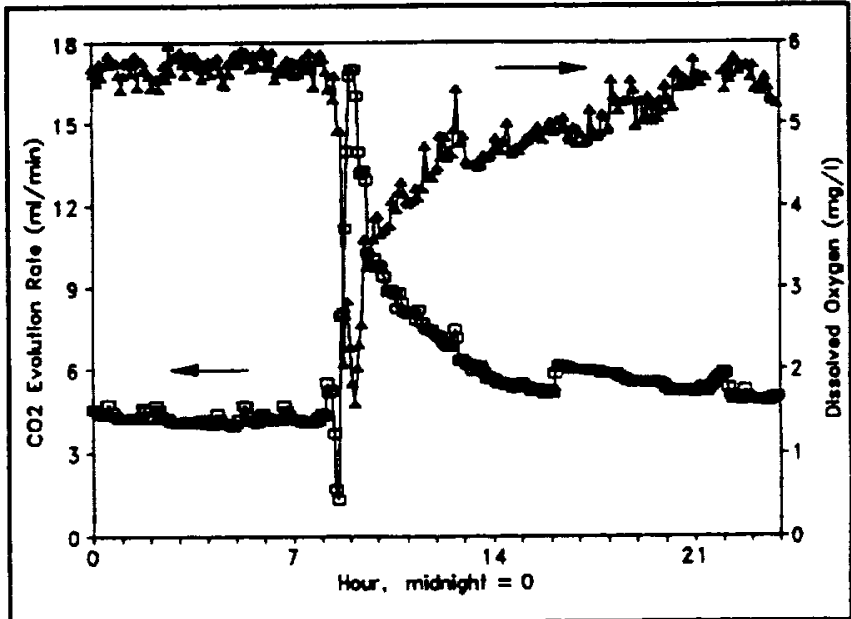

Figure 4. Typical plots of $\mathrm{CO}_{2}$ production and dissolved oxygen concentration for a 24 hour period.

whereas the steady increase in $\mathrm{CO}_{2}$ production rates reflect the buildup of slower growing microbes that degrade plant cellulose and hemicellulose.

For comparison with dry weight losses, the total amount of carbon dioxide produced during each run was calculated and converted into a percentage of the total carbon added as residue. Dreschel (13) reported that BPC grown wheat contained ca. $40 \%$ carbon (ultimate analysis), so this conversion factor was used. In further support for using this conversion factor, inost of the crop residue was carbohydrate, which contain from 40 to $45 \%$ carbon, depending on the degree of polymerization. Total $\mathrm{CO}_{2}$ production values are listed in Table 1 . With carbon mineralization as the response variable, the lower solids addition rate of $20 \mathrm{gdw}$ day $^{-1}$ gave highest conversion values. The lower culture replacement rate was slightly better than the higher one of $1 / 4$ volume per day. Surprisingly, solids recycling did little to stimulate carbon conversion. 


\begin{tabular}{|c|c|c|c|c|c|}
\hline \multirow[b]{2}{*}{ Component } & \multirow{2}{*}{$\begin{array}{l}\text { Bioreactor } \\
\text { Effluent } \\
\text { (ppm) }\end{array}$} & \multirow[b]{2}{*}{$\begin{array}{l}\text { Leachate } \\
\text { (ppm) }\end{array}$} & \multirow[b]{2}{*}{$\begin{array}{l}\text { Hoagland } \\
\text { (ppm) }\end{array}$} & \multirow{2}{*}{$\begin{array}{c}\text { Effluent } \\
\begin{array}{c}\text { Leachate } \\
(\%)\end{array}\end{array}$} & \multirow{2}{*}{ as $\quad$ Percent $\begin{array}{c}\text { Hoagland } \\
(\%)\end{array}$} \\
\hline & & & & & \\
\hline $\mathrm{NO}_{3}-\mathrm{N}$ & 386 & 266 & 1050 & 145 & 37 \\
\hline $\mathrm{PO}_{4}-\mathrm{P}$ & 40 & 42 & 233 & 94 & 17 \\
\hline$K$ & 1618 & 1927 & 2652 & 84 & 61 \\
\hline $\mathrm{Ca}$ & 145 & 157 & 300 & 92 & 48 \\
\hline $\mathrm{Mg}$ & 102 & 121 & 238 & 84 & 43 \\
\hline $\mathrm{Fe}$ & 0.71 & 2.66 & 11.1 & 27 & 6 \\
\hline $\mathrm{Cu}$ & 0.57 & 0.20 & 0.6 & 285 & 95 \\
\hline$M n$ & 1.38 & 1.49 & 3.73 & 93 & 37 \\
\hline $\mathrm{Zn}$ & 0.63 & 0.20 & 3.73 & 315 & 17 \\
\hline Mo & $<0.01$ & $<0.01$ & 0.94 & - & 0 \\
\hline B & 1.31 & 1.91 & 0.94 & 69 & 139 \\
\hline $\mathrm{CO}_{2}-\mathrm{C}$ & YES & NO & NO & & \\
\hline $\begin{array}{l}\text { microbial } \\
\text { biomass }\end{array}$ & YES & NO & NO & & \\
\hline
\end{tabular}

The short duration of these initial I-SAB runs was inadequate to support tests of the ability of bioreactor effluent to regenerate plant nutrient solutions. A wheat production study was designed by KSC crop scientists to compare regenerated wheat hydroponic solutions with Hoagland's solution. Three different sources of solution were tested: A standard Hoagland's solution (control), leachate from BWT931 wheat residues, and effluent from bioreactors fedBWT931 wheat residues. Details of this study are being published elsewhere (8). The intermediate-scale aerobic bioreactor was used with $1 / 8$ culture replacement, $40 \mathrm{gdw}$ residue added per day, and no solids recycling. Environmental conditions were the same as for the earlier runs: $\mathrm{pH} 6.5$, temperature $35^{\circ} \mathrm{C}$, air flow $5 \mathrm{~L} \mathrm{~min}{ }^{-1}$. The duration of this run was 76 days. At day 23 , the rapid vegetative growth of the test plants out-paced the ability of I-SAB \#1 to supply effluent so I-SAB \#2 was started with a $50 \%$ inoculum from I-SAB \#1. I-SAB \#2 ran for 47 days.

Response variables for the bioreactors were $\mathrm{CO}_{2}$ production and inorganic content of the bioreactor effluent. Figure 5 shows production of $\mathrm{CO}_{2}$ by both bioreactors. Microbial decomposition in I-SAB \#1 was quite variable, indicating that the microbial community was not stable. In general, rates tended to decline

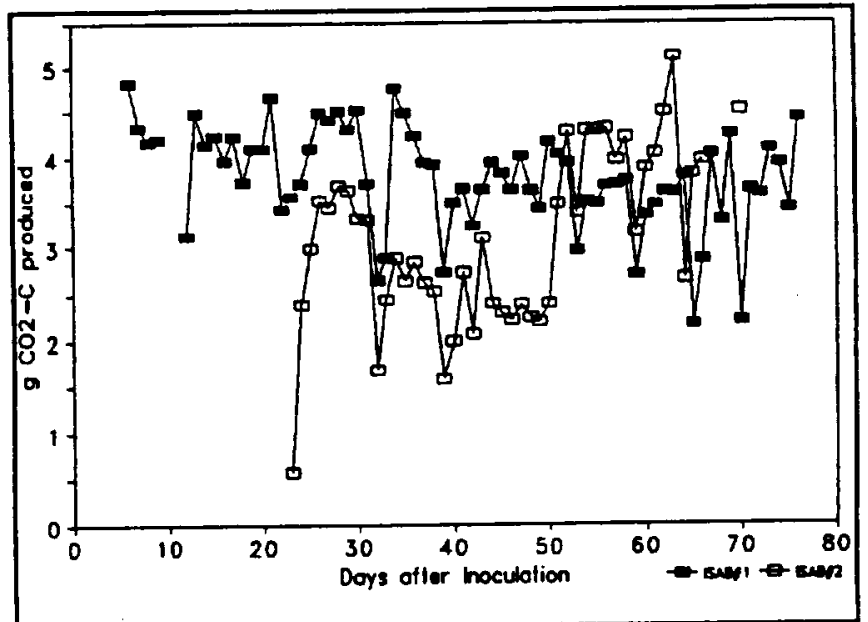

Figure 5. Time-courses of daily $\mathrm{CO}_{2}$ production for $1-\mathrm{SAB} \# 1$ and I-SAB\#2 during the wheat grow-out experiment.

after ca. day 40 . However, many of the abnormally high or low values could be explained by equipment or computer control problems. At the end of each run, after crop growth requirements had been satisfied, the effect of air flow perturbation on various microbiological parameters was examined. These 
perturbations, which usually lasted for one day, are reflected in low values for carbon dioxide production as the bioreactor went anaerobic.

As shown in Table II, recovery of major cations and anions, i.e., nitrate, phosphate, potassium, calcium, and magnesium, from the wheat residues in the bioreactor effluent was comparable to aqueous extraction (leaching) results using the same wheat residue from BWT931. Effluent contained higher amounts of nitrate, probably due to $\mathrm{pH}$ control by addition of appropriate amounts of $1 \mathrm{~N}$ nitric acid. Bioreactor recovery of trace elements depended on the element. Iron recovery was poor and probably reflects immobilization by microbial cells, when compared with leachate. Recovery of copper and zinc was much better than for leachate.

Both leachate and bioreactor effluent mineral recovery systems use only inedible crop residues as starting material. The portion of minerals contained in edible biomass must also be recovered after passage through food processing and crew components of a CELSS. As a result, neither bioreactor effluent nor leachate were expected to recover all of the minerals needed to replenish a hydroponic solution.

For the wheat growth study on nutrient recycling, inorganic salts were added to the effluent or leachate, after results of inorganic analyses were known, to bring total concentration of each element to the same levels as were in the Hoagland's control replenishment solution. Results of the wheat growth tests showed that bioreactor effluent, so amended, could be used successfully to replenish the nutrient solution of hydroponically grown wheat (8).

\section{SUMMARY AND CONCLUSIONS}

Three Intermediate-Scale Aerobic Bioreactors were designed, fabricated and operated at the Kennedy Space Center's CELSS Breadboard Project. The bioreactors were successfully used to maintain, monitor, and control aerobic biodegradation experiments. These experiments focused on the characterization of the microbial mineralization process of inedible plant biomass, and the identification of optimum process parameters. Liquid effluent from the biodegradation process was shown to contain sufficient inorganic nutrient levels to support the hydroponic growth of candidate CELSS food-crops.

The I-SAB's are currently being used to further investigate aerobic degradation of inedible biomass. Bioreactor effluent is being used in long-term plant growth experiments that focus on the continuous production of white potatoes. In addition, I-SAB 3 has been modified to support anaerobic biodegradation studies and is currently being used for that purpose.

Results from the I-SAB aerobic processing experiments have been used to design a larger Breadboard-Scale Aerobic Bioreactor (B-SAB) that will be integrated with KSC's BPC to investigate large-scale recycling of inorganic nutrients. Protocols are also being developed to conduct fish feeding trials using harvested biomass from B-SAB.

\section{REFERENCES}

(1) Strayer, R.F.. "Evaluation of Enzymatic Hydrolysis of CELSS Wheat Residue Cellulose at a Scale Equivalent to NASA's KSC Breadboard Project", SAE Technical Paper Series No. 932253, Presented at the 23rd International Conference on Environmental Systems (ICES), 1993.

Garland, J.L., "Coupling Plant Growth and Waste Recycling Systems in a Controlled Ecological Life Support System (CELSS)", NASA Tech. Memorandum 107544, 1992.

Garland, J.L., "Characterization of the Water Soluble Component of Inedible Residue From Candidate CELSS Crops", NASA Tech. Memorandum 107557, 1992.

(4) Garland, J.L., Mackowiak, C.L., Sager, J.C., "Hydroponic Crop Production Using Recycled Nutrients From Inedible Crop Residues", SAE Technical Paper Series 932173, Presented at the 23rd International Conference on Environmental Systems (ICES), 1993.

McNeil, B. Harvey, L.M., (Ed.), Fermentation, A Practical Approach, Oxford, England, Information Press, Ltd., 1990.

Kassen, N.W.F., "Bioreactor Consolidation and Innovation", Paper presented at the 3rd EFB Conference, Munich, 10-14 September, 1984.

Bailey, J.E., Ollis, D.F., Biochemical Engineering Fundamentals, 2nd Edition, New York, McGraw-Hill, 1986

(8). Mackowiak, C.L., Garland, J.L., Strayer, R.F., Finger, B.W., Ruffin, T.J., "Comparison of Aerobically Treated And Untreated Crop Residue as a Source of Recycled Nutrients In a Recirculating Hydroponic System",paper in publication to be presented at the 30th COSPAR Scientific Assembly, Hamburg, Germany, 11-21 July, 1994.

Tatterson, G.B., Scale-Up and Design of Industrial Mixing Processes, New York, McGraw-Hill, 1994.

Riet, K., Tramper, J., Basic Bioreactor Design, New York, Marcell Dekker, 1991.

Bledsoe, J.O., Sager, J.C., Fortson, R.E., "Network Data Acquisition and Control for 
Environmental Chambers", ASAE Paper No. 933510, ASAE Winter Meeting, Chicago, 12-17

December, 1993.

(12) Atkison, B., Biochemical Engineering and Biotechnology Handbook, 2nd Edition, New York, Macmillan, 1991.

(13) Dreschel, T.W., Wheeler, R.M., Hinkle, C.R., Sager, J.C., Knott, W.M., Investigating Combustion As a Method of Processing Inedible Biomass Produced in NASA's Biomass Production Chamber. NASA Tech. Memorandum 103821, 1991. 
